\title{
BMJ Open Chronic symptoms in a representative sample of community-dwelling older people: a cross-sectional study in Switzerland
}

Yves Henchoz, ${ }^{1}$ Christophe Büla, ${ }^{2}$ Idris Guessous, ${ }^{3,4}$ Nicolas Rodondi, ${ }^{5,6}$ René Goy, ${ }^{7}$ Maurice Demont, ${ }^{8}$ Brigitte Santos-Eggimann ${ }^{1}$

To cite: Henchoz Y, Büla C, Guessous I, et al. Chronic symptoms in a representative sample of communitydwelling older people: a cross-sectional study in Switzerland. BMJ Open 2017;6:e014485. doi:10.1136/bmjopen-2016014485

- Prepublication history and additional material is available. To view please visit the journal (http://dx.doi.org/ 10.1136/bmjopen-2016014485).

Received 27 September 2016 Revised 4 November 2016 Accepted 25 November 2016

CrossMark

For numbered affiliations see end of article.

Correspondence to Dr Yves Henchoz; yves.henchoz@chuv.ch

\section{ABSTRACT}

Objectives: The burden of multiple diagnoses is well documented in older people, but less is known about chronic symptoms, many of which are even not brought to medical attention. This study aimed to determine the prevalence of chronic symptoms, their relationships with disability in basic activities of daily living (BADL) and quality of life (QoL), and their public health impact. Design: A large cross-sectional population-based study.

Setting: Community in 2 regions of French-speaking Switzerland.

Participants: Community-dwelling older adults aged 68 years and older in 2011 ( $\mathrm{N}=5300$ ).

Outcomes: Disability in BADL defined as difficulty or help needed with any of dressing, bathing, eating, getting in/out of bed or an arm chair, and using the toilet. Overall QoL dichotomised as favourable (ie, excellent or very good) or unfavourable (ie, good, fair or poor). Disturbance by any of the following 14 chronic symptoms for at least 6 months: joint pain, back pain, chest pain, dyspnoea, persistent cough, swollen legs, memory gaps, difficulty concentrating, difficulty making decisions, dizziness/vertigo, skin problems, stomach/intestine problems, urinary incontinence and impaired sexual life.

Results: Only $17.1 \%$ of participants did not report being disturbed by any of these chronic symptoms. Weighted prevalence ranged from $3.1 \%$ (chest pain) to $47.7 \%$ (joint pain). Most chronic symptoms were significantly associated with disability in BADL or unfavourable QoL, with substantial gender differences. The number of chronic symptoms was significantly associated with disability in BADL and unfavourable QoL, with gradients suggesting dose-response

relationships. Joint pain and back pain had the highest population attributable fractions.

Conclusions: Chronic symptoms are highly prevalent in older people, and are associated with disability in BADL and unfavourable QoL, particularly when multiple chronic symptoms co-occur. Owing to their high public health impact, musculoskeletal chronic symptoms represent good targets for preventive interventions.

\section{Strengths and limitations of this study}

- This study is based on a representative sample of community-dwelling older men and women.

- Data from the Lausanne cohort 65+ (Lc65+) cohort study allowed adjusting for a substantial number of potential confounders.

- In addition to 14 chronic symptoms assessed in the present study, others may have been considered, such as headache, tiredness, impaired hearing/sight and sleeping problems.

- Each chronic symptom was recorded as present or absent, without attempting to assess severity.

- The study's cross-sectional design precludes any causal inference.

\section{INTRODUCTION}

Symptoms account for over half of all outpatient visits, ${ }^{1}$ even though many individuals who suffer from symptoms do not consult. This phenomenon has been referred to as the 'symptom iceberg'. ${ }^{2}$ The visible part represents the proportion of symptoms known to the general practitioner, whereas the submerged part encompasses symptoms which are not brought to medical attention. Faced with the complexity of the whole human body, biomedical research has favoured objective over subjective outcomes, and has therefore largely focused on medical diagnoses rather than on symptoms. However, a comprehensive overview of a patient's symptomatology is certainly meaningful when trying to fully understand his or her burden. ${ }^{3}$

Most studies on symptom prevalence have been conducted in a clinical setting. Not only did a limited number of populationbased studies investigated this issue, many of these focused on middle-aged adults ${ }^{4-8}$ or even exclusively on middle-aged women. ${ }^{9} 10$ Similarly, many studies on older people focused on a single symptom such as back 
pain, ${ }^{11}$ neuropsychiatric, ${ }^{12}$ anxiety ${ }^{13}$ or urinary $^{14}$ symptoms. Furthermore, the few studies that considered multiple symptoms enrolled only small samples, ${ }^{15-17}$ or older persons with severe comorbidities ${ }^{18}$ or advanced chronic diseases. ${ }^{19}$ As a result, little is known about symptom burden in community-dwelling older people.

Common symptoms generally relapse within a few weeks, but a quarter persist over time and often require more comprehensive management. ${ }^{1}$ Also, there is strong evidence that the prevalence of chronic conditions substantially increases with age, and that multimorbiditythe coexistence of multiple chronic conditions-is associated with poor functional status, quality of life (QoL) and health outcomes. ${ }^{20}$ Such associations have also been found when considering symptoms not reported to the physician, although more scarcely. In a cross-sectional study including older adults with high rates of comorbid diagnoses, symptoms correlated with mobility function at least as strongly as-if not more strongly than-a list of diseases did. ${ }^{18}$ Nevertheless, the epidemiology of chronic symptoms still needs to be investigated in more details in older people. From a public health perspective, a better understanding of the prevalence of chronic symptoms would help healthcare policies to focus on chronic symptoms that strongly affect functional status and QoL.

This study sought to determine the prevalence of chronic symptoms in older men and women, their associations with disability in basic activities of daily living (BADL) and QoL, and their public health impact.

\section{METHODS}

\section{Study design and population}

This cross-sectional study used data from the populationbased Lausanne cohort $65+$ study $(\text { Lc65+ })^{21}$ and two additional, stratified, random samples selected from population lists in the cantons of Vaud and Geneva. ${ }^{22}$ The pooled data set comprising 5300 community-dwelling adults aged 68 years and older is representative of older people in two French-speaking Swiss regions. Persons living in institutions or unable to respond by themselves due to significant cognitive impairment or advanced dementia were excluded. More details on participants' enrolment can be found elsewhere. ${ }^{22}$ In brief, data were collected by means of a postal questionnaire in 2011 with a response rate of $71.2 \%$ (5300 out of 7443 eligible participants). The response rate was higher in participants from the Lc65+ cohort (95\%) than in those from the stratified random samples $(60 \%)$. This difference most likely reflects the motivation and adherence of Lc65+ participants who have been followed yearly since 2004. Small differences were observed according to sex, age and canton. ${ }^{22}$

\section{Measures}

Chronic symptoms

Respondents were asked whether they had been disturbed by any of the following 14 chronic symptoms for at least 6 months: joint pain, back pain, chest pain (on exertion), dyspnoea, persistent cough, swollen legs, memory gaps (affecting daily life), difficulty concentrating, difficulty making decisions (in daily life), dizziness or vertigo, skin problems (eg, eczema, psoriasis), stomach/intestine problems (including diarrhoea and constipation), urinary incontinence and impaired sexual life (due to pain, decreased sex drive, erectile dysfunction, etc). This list of chronic symptoms was adapted from the methodology of the Survey of Health, Aging, and retirement in Europe (SHARE) ${ }^{23}$ Owing to very high bivariate associations between memory gaps, difficulty concentrating and difficulty making decisions (see online supplementary table S1), they were grouped into 'mental impairments', defined as the presence of any of these three symptoms.

\section{Disability in BADL}

Disability in BADL was assessed using five items of the Katz Index. ${ }^{24}$ Although little evidence has been published on the psychometric properties of the Katz Index, it is one of the most frequently used tools to assess disability in older people. ${ }^{25}$ Participants indicated whether they had had difficulty dressing, bathing, eating, getting in/out of bed or an arm chair, and using the toilet over the past 4 weeks. Continence was not included, as in the large majority of studies incorporating the Katz Index. ${ }^{26}$ Response choices were 'no difficulty', 'difficulty but no help' or 'received help'. Disability in BADL was dichotomised as 'yes' (ie, participants reporting 'difficulty but no help' and those reporting 'received help' with one or more of the five BADL) or 'no' (ie, participants reporting 'no difficulty' in all five BADL).

\section{Quality of life}

Overall QoL was assessed with a single item: 'How do you rate your current QoL?' Answers ranged from 'excellent' to 'very good', 'good', 'fair' and 'poor'. Corresponding response choices in the French version of the SF-36 were used. ${ }^{27} \mathrm{~A}$ single global rating of QoL is a valid and sensible measure, as far as the purpose to assess QoL-in the broad sense-is concerned. ${ }^{28}$ It may even be preferable to multidimensional scales ${ }^{29}$ which are more appropriate for a detailed QoL assessment. Unfavourable QoL was defined as an answer other than 'excellent' and 'very good' (ie, good, fair or poor). In a recent study, ${ }^{30}$ applying different cut-offs on the excellent-to-poor scale so as to define favourable QoL resulted in important changes in the type as well as in the number of significant QoL determinants. Dichotomising QoL as being at least very good (ie, excellent/very good vs good/fair/poor) was the only model that yielded significant determinants in every health, economic and social dimensions. Therefore, this cut-off appears to best reflect the multidimensional nature of QoL.

\section{Covariates}

At the stage of study sampling and recruitment, the Residents' Registration Office provided information 
about residents' age, gender, canton of residence and commune of residence. The latter was used to determine whether or not participants were living in the main city of the canton of Vaud (Lausanne) or the canton of Geneva (Geneva). Additional information was gathered by means of a postal questionnaire that provided information about living arrangement (alone; with others), Swiss citizenship, ever having children, highest level of education achieved ('basic compulsory' (International Standard Classification of Education (ISCED ${ }^{31}$ ) level 0-2); 'apprenticeship' (ISCED level 3); 'post-compulsory' (ISCED level 4-8)), financial difficulties (defined as answering 'yes' to the question 'Are you sometimes struggling to make ends meet?'), and the presence of depressive symptoms. The latter was defined as answering 'yes' to either of the two following questions of the Primary Care Evaluation of Mental Disorders Procedure: 'During the past month, have you often been bothered by (1) feeling down, depressed or hopeless? (2) little interest or pleasure in doing things?' As compared with a standardised interview, these two questions had a sensitivity of $96 \%$ and a specificity of $57 \%$ in diagnosing depression. ${ }^{32}$ Education and financial difficulties served as indicators of the socioeconomic status.

\section{Statistical analysis}

All analyses were stratified by gender because of the expected differences in QoL and in the prevalence of disability and chronic conditions between women and men. ${ }^{33}$ Sampling weights were used to account for unequal selection probabilities and response.

The association between chronic symptoms and disability in BADL was assessed using multiple logistic regression analyses, which were conducted separately for each chronic symptom. Models were adjusted for covariates (model 1), and additionally for the number of other chronic symptoms (model 2). The association between each chronic symptom and unfavourable QoL was also assessed using models 1 and 2. A third model was additionally adjusted for disability in BADL to assess the association between each chronic symptom and unfavourable QoL over and above the contribution of disability in BADL (model 3). Multiple logistic regression models were also used to assess the association between the number of chronic symptoms and both disability in BADL and unfavourable QoL (model 1 only). Dose-response relationship was assessed by entering the number of chronic symptoms into model 1 as a continuous variable. All models were rerun by combining women and men to test interactions between gender and chronic symptoms.

To estimate the proportion of disability in BADL or unfavourable QoL that may be hypothetically reduced by the elimination of each chronic symptoms, population attributable fraction (PAF) was calculated using the user-written command 'punaf' in Stata. ${ }^{35}$ After fitting a logistic regression (model 2), this command follows the method recommended by Greenland and Drescher ${ }^{36}$ for cohort and cross-sectional studies to calculate the $\mathrm{PAF}$ and its $95 \% \mathrm{CI}$.

Since missing values were likely to be missing at random, they were imputed using multiple imputations with chained equations. ${ }^{37}$ Fifty imputation data sets were created. PAF was calculated using complete-case analysis, because the 'punaf' command does not support multiple imputations. Analyses were conducted using Stata V.14.0 software (StataCorp, College Station, Texas, USA). Significance was set at $\mathrm{p}<0.05$.

\section{RESULTS}

Socioeconomic and demographic characteristics

Table 1 shows the characteristics of participants. Compared with men, women were older, were more often living in a main city, and reported higher rates of Swiss citizenship, 'alone' living arrangement and 'no' children status, a lower level of education, a higher rate of depressive symptoms, and a less favourable QoL (all $\mathrm{p} \leq 0.001$ ). There was no significant gender difference in the canton of residence, financial difficulties and disability in BADL.

\section{Prevalence of chronic symptoms}

Most pairwise associations between chronic symptoms were significant (see online supplementary table S1). In other words, participants reporting a given chronic symptom were more likely to report almost any other chronic symptom. As indicated in table 2 , joint pain was the most prevalent chronic symptom in women $(51.5 \%)$ and men $(42.5 \%)$. At the other end of the spectrum, the prevalence of chest pain was only around $3 \%$ regardless of gender. Four chronic symptoms (ie, mental impairments, skin problems, persistent cough and chest pain) did not display any significant gender difference. In contrast, impaired sexual life was dramatically more prevalent in men $(33.9 \%)$ than in women $(4.5 \%)$. All seven remaining chronic symptoms (ie, joint pain, back pain, stomach/intestine problems, urinary incontinence, dyspnoea, swollen legs and dizziness/vertigo) were more prevalent in women than in men. This translated in a higher proportion of women than men with 3,4 or $\geq 5$ chronic symptoms $(\mathrm{p}=0.002)$.

\section{Associations between chronic symptoms and disability in BADL}

Table 3 indicates the gender-specific associations between chronic symptoms and disability in BADL. In model 1-adjusted for socioeconomic and demographic characteristics-all chronic symptoms were significantly associated with disability in BADL, except impaired sexual life in women, and impaired sexual life, skin problems and persistent cough in men. These associations were attenuated in model 2, further adjusted for the number of other chronic symptoms. Several chronic symptoms remained significantly associated with 
Table 1 Characteristics of study participants (weighted percentages)

\begin{tabular}{|c|c|c|c|c|}
\hline & Total sample $(n=5300)$ & Women $(n=2781)$ & Men $(n=2519)$ & p Value* \\
\hline \multicolumn{5}{|l|}{ Age $(n=5300)$} \\
\hline $68-72$ years & $32.6 \%$ & $30.7 \%$ & $35.1 \%$ & \multirow[t]{3}{*}{0.001} \\
\hline $73-77$ years & $24.9 \%$ & $23.7 \%$ & $26.4 \%$ & \\
\hline $78-99$ years & $42.6 \%$ & $45.6 \%$ & $38.5 \%$ & \\
\hline \multicolumn{5}{|c|}{ Canton of residence $(n=5300)$} \\
\hline Geneva & $41.5 \%$ & $41.9 \%$ & $41.0 \%$ & \multirow[t]{2}{*}{0.641} \\
\hline Vaud & $58.5 \%$ & $58.1 \%$ & $59.0 \%$ & \\
\hline \multicolumn{5}{|l|}{ Main city $(n=5300)$} \\
\hline No & $71.4 \%$ & $69.3 \%$ & $74.3 \%$ & \multirow[t]{2}{*}{0.001} \\
\hline Yes & $28.6 \%$ & $30.7 \%$ & $25.7 \%$ & \\
\hline \multicolumn{5}{|c|}{ Swiss citizenship $(n=5230)$} \\
\hline No & $13.4 \%$ & $11.4 \%$ & $16.1 \%$ & \multirow[t]{2}{*}{$<0.001$} \\
\hline Yes & $86.6 \%$ & $88.6 \%$ & $83.9 \%$ & \\
\hline \multicolumn{5}{|c|}{ Living arrangement $(n=5228)$} \\
\hline Alone & $37.6 \%$ & $52.7 \%$ & $17.0 \%$ & \multirow[t]{2}{*}{$<0.001$} \\
\hline With others & $62.4 \%$ & $47.3 \%$ & $83.0 \%$ & \\
\hline \multicolumn{5}{|c|}{ Ever having children $(n=5232)$} \\
\hline No & $15.2 \%$ & $17.5 \%$ & $11.9 \%$ & \multirow[t]{2}{*}{$<0.001$} \\
\hline Yes & $84.8 \%$ & $82.5 \%$ & $88.1 \%$ & \\
\hline \multicolumn{5}{|l|}{ Education $(n=5203)$} \\
\hline Basic compulsory & $24.9 \%$ & $31.6 \%$ & $15.7 \%$ & \multirow[t]{3}{*}{$<0.001$} \\
\hline Apprenticeship & $35.5 \%$ & $33.9 \%$ & $37.7 \%$ & \\
\hline Postcompulsory & $39.6 \%$ & $34.5 \%$ & $46.7 \%$ & \\
\hline \multicolumn{5}{|c|}{ Financial difficulties $(n=4795)$} \\
\hline No & $85.9 \%$ & $84.8 \%$ & $87.5 \%$ & \multirow[t]{2}{*}{0.059} \\
\hline Yes & $14.1 \%$ & $15.8 \%$ & $12.5 \%$ & \\
\hline \multicolumn{5}{|c|}{ Depressive symptoms $(n=5160)$} \\
\hline No & $73.2 \%$ & $68.8 \%$ & $79.1 \%$ & \multirow[t]{2}{*}{$<0.001$} \\
\hline Yes & $26.8 \%$ & $31.2 \%$ & $20.9 \%$ & \\
\hline \multicolumn{5}{|c|}{ Disability in BADL $(n=5202)$} \\
\hline No & $73.9 \%$ & $72.6 \%$ & $75.6 \%$ & \multirow[t]{2}{*}{0.100} \\
\hline Yes & $26.1 \%$ & $27.4 \%$ & $24.4 \%$ & \\
\hline \multicolumn{5}{|l|}{ Quality of life ( $n=4847)$} \\
\hline Favourable & $49.5 \%$ & $46.7 \%$ & $53.4 \%$ & \multirow[t]{2}{*}{$<0.001$} \\
\hline Unfavourable & $50.5 \%$ & $53.3 \%$ & $46.6 \%$ & \\
\hline
\end{tabular}

disability in BADL in both genders (ie, joint pain, back pain, urinary incontinence and swollen legs), or only in women (ie, dizziness/vertigo $(\mathrm{OR}=1.7 ; \mathrm{p}=0.019)$ and skin problems $(\mathrm{OR}=2.8 ; \mathrm{p}<0.001)$ ) or men (ie, mental impairments $(\mathrm{OR}=1.7 ; \mathrm{p}=0.003)$ ). In women and men, the number of chronic symptoms was significantly associated with disability in BADL. When the number of chronic symptoms was entered into model 1 as a continuous variable (not indicated in table 3), the positive dose-response relationship between the number of chronic symptoms and disability in BADL was confirmed in women $(\mathrm{OR}=1.57 ; \mathrm{p}<0.001)$ and men $(\mathrm{OR}=1.43 ; \mathrm{p}<0.001)$. The interaction between gender and skin problems was significant in model $1(\mathrm{p}=0.001)$ and model $2(\mathrm{p}<0.001)$, thereby indicating a significant association between skin problems and disability in BADL restricted to women. All other interactions between gender and chronic symptoms were not significant.
Associations between chronic symptoms and unfavourable QoL

As indicated in table 4 (model 1 ), half of chronic symptoms were significantly associated with unfavourable QoL in women (ie, joint pain, back pain, stomach/intestine problems, dyspnoea, swollen legs and skin problems). In men, all but two chronic symptoms (impaired sexual life and skin problems) were significantly associated with unfavourable QoL. After adjusting for the number of other chronic symptoms (model 2), all associations were attenuated. Two chronic symptoms in women (ie, joint pain and back pain) and five chronic symptoms in men (ie, joint pain, mental impairments, dyspnoea, persistent cough and chest pain) remained significantly associated with unfavourable QoL. Further adjustment for disability in BADL (model 3) only slightly changed the associations obtained in model 2. In women and men, the number of chronic symptoms was significantly associated with unfavourable QoL. Entering 
Table 2 Weighted prevalence of chronic symptoms

\begin{tabular}{lcccc}
\hline & Total sample (n=5191) & Women (n=2737) & Men (n=2454) \\
\hline Joint pain & $47.7 \%(45.7 \%$ to $49.7 \%)$ & $51.5 \%(48.6 \%$ to $54.3 \%)$ & $42.5 \%(39.9 \%$ to $45.1 \%)$ & $<0.001$ \\
Back pain & $34.7 \%(32.8 \%$ to $36.5 \%)$ & $38.2 \%(35.4 \%$ to $40.9 \%)$ & $29.8 \%(27.4 \%$ to $32.2 \%)$ & $<0.001$ \\
Stomach/intestine problems & $22.1 \%(20.5 \%$ to $23.8 \%)$ & $26.3 \%(23.8 \%$ to $28.9 \%)$ & $16.4 \%(14.4 \%$ to $18.3 \%)$ & $<0.001$ \\
Mental impairments & $18.3 \%(16.7 \%$ to $19.9 \%)$ & $19.0 \%(16.8 \%$ to $21.3 \%)$ & $17.3 \%(15.3 \%$ to $19.3 \%)$ & 0.288 \\
Urinary incontinence & $17.4 \%(15.8 \%$ to $19.0 \%)$ & $21.4 \%(19.0 \%$ to $23.8 \%)$ & $11.9 \%(10.2 \%$ to $13.7 \%)$ & $<0.001$ \\
Impaired sexual life & $16.9 \%(15.6 \%$ to $18.1 \%)$ & $4.5 \%(3.4 \%$ to $5.6 \%)$ & $33.9 \%(31.4 \%$ to $36.3 \%)$ & $<0.001$ \\
Dyspnoea & $16.9 \%(15.4 \%$ to $18.5 \%)$ & $18.4 \%(16.2 \%$ to $20.7 \%)$ & $14.9 \%(13.0 \%$ to $16.8 \%)$ & 0.022 \\
Swollen legs & $13.4 \%(12.0 \%$ to $14.7 \%)$ & $14.8 \%(12.8 \%$ to $16.9 \%)$ & $11.3 \%(9.6 \%$ to $13.0 \%)$ \\
Dizziness/vertigo & $10.3 \%(9.0 \%$ to $11.6 \%)$ & $12.2 \%(10.2 \%$ to $14.1 \%)$ & $7.7 \%(6.3 \%$ to $9.1 \%)$ \\
Skin problems & $9.8 \%(8.6 \%$ to $11.0 \%)$ & $9.3 \%(7.6 \%$ to $11.0 \%)$ & $10.5 \%(8.9 \%$ to $12.2 \%)$ \\
Persistent cough & $4.6 \%(3.8 \%$ to $5.4 \%)$ & $5.0 \%(3.8 \%$ to $6.1 \%)$ & $4.1 \%(3.0 \%$ to $5.1 \%)$ \\
Chest pain & $3.1 \%(2.3 \%$ to $3.8 \%)$ & $3.3 \%(2.2 \%$ to $4.4 \%)$ & $2.7 \%(1.9 \%$ to $3.6 \%)$ \\
Number of chronic symptoms $)$ & 0.285 \\
$\quad 0$ & $17.1 \%(15.7 \%$ to $18.6 \%)$ & $15.9 \%(13.9 \%$ to $17.8 \%)$ & $18.9 \%(16.8 \%$ to $21.0 \%)$ \\
1 & $24.9 \%(23.2 \%$ to $26.6 \%)$ & $24.1 \%(21.7 \%$ to $26.5 \%)$ & $26.0 \%(23.7 \%$ to $28.3 \%)$ \\
2 & $22.0 \%(20.3 \%$ to $23.6 \%)$ & $21.9 \%(19.5 \%$ to $24.2 \%)$ & $22.1 \%(19.9 \%$ to $24.4 \%)$ \\
3 & $16.8 \%(15.3 \%$ to $18.4 \%)$ & $17.6 \%(15.4 \%$ to $19.8 \%)$ & $15.8 \%(13.8 \%$ to $17.7 \%)$ \\
4 & $9.3 \%(8.2 \%$ to $10.5 \%)$ & $9.8 \%(8.1 \%$ to $11.5 \%)$ & $8.7 \%(7.2 \%$ to $10.2 \%)$ \\
$\geq 5$ & $9.8 \%(8.6 \%$ to $11.1 \%)$ & $10.8 \%(8.9 \%$ to $12.7 \%)$ & $8.5 \%(7.0 \%$ to $10.0 \%)$
\end{tabular}

Data are weighted prevalence $(95 \% \mathrm{Cls})$.

*Logistic regression.

Table 3 Associations between chronic symptoms and disability in BADL (ORs)

\begin{tabular}{|c|c|c|c|c|}
\hline \multirow[b]{2}{*}{ Chronic symptoms } & \multicolumn{2}{|c|}{ Women $(n=2318)$} & \multicolumn{2}{|c|}{ Men $(n=2132)$} \\
\hline & Model 1† & Model 2† & Model 1† & Model 2† \\
\hline Joint pain & $1.8^{\star \star \star}$ & $1.4^{*}$ & $2.4^{\star \star *}$ & $2.1^{\star \star \star}$ \\
\hline Back pain & $2.2^{\star \star \star}$ & $1.7^{\star \star}$ & $2.3^{\star * *}$ & $2.0^{* * *}$ \\
\hline Stomach/intestine problems & $1.5^{\star}$ & 1.1 & $1.7^{\star \star}$ & 1.3 \\
\hline Mental impairments & $1.9^{\star *}$ & 1.5 & $2.0^{\star * *}$ & $1.7^{\star \star}$ \\
\hline Urinary incontinence & $2.2^{\star * *}$ & $1.8^{\star \star}$ & $2.5^{\star \star *}$ & $1.9^{\star \star}$ \\
\hline Impaired sexual life & 1.5 & 1.2 & 1.0 & 0.9 \\
\hline Dyspnoea & $2.0^{\star \star \star}$ & 1.4 & $1.9^{\star \star *}$ & 1.4 \\
\hline Swollen legs & $3.0^{* * *}$ & $2.2^{\star \star \star}$ & $2.5^{\star \star *}$ & $1.7^{*}$ \\
\hline Dizziness/vertigo & $2.4^{* * *}$ & $1.7^{\star}$ & $1.8^{*}$ & 1.2 \\
\hline Skin problems & $3.2^{* * *}$ & $2.8^{\star * *}$ & 1.0 & 0.8 \\
\hline Persistent cough & $1.8^{*}$ & 1.2 & 1.3 & 0.9 \\
\hline Chest pain & $2.9^{\star \star}$ & 1.7 & $2.0^{*}$ & 1.1 \\
\hline \multicolumn{5}{|l|}{ Number of chronic symptoms } \\
\hline 0 & Ref & & Ref & \\
\hline 1 & $2.0^{*}$ & & $4.3^{\star \star \star}$ & \\
\hline 2 & $2.6^{\star \star}$ & & $9.0^{\star * *}$ & \\
\hline 3 & $3.9^{\star \star \star}$ & & $10.1^{\star \star \star}$ & \\
\hline 4 & $4.8^{* * *}$ & & $12.3^{\star \star \star}$ & \\
\hline$\geq 5$ & $20.1^{\star \star \star}$ & & $18.0^{\star \star \star}$ & \\
\hline
\end{tabular}

${ }^{*} \mathrm{p}<0.05 ;{ }^{* *} \mathrm{p}<0.01 ;{ }^{* * *} \mathrm{p}<0.001$.

†Logistic regression; model 1: adjusted for age, canton of residence, main city, Swiss citizenship, living arrangement, children, education, financial difficulties and depressive symptoms; model 2: adjusted for covariates in model 1 and the number of other chronic symptoms.

BADL, basic activities of daily living.

the number of chronic symptoms into model 1 as a continuous variable (not indicated in table 4) confirmed the positive dose-response relationship between the number of chronic symptoms and unfavourable QoL in women $\quad(\mathrm{OR}=1.32 ; \mathrm{p}<0.001)$ and men $\quad(\mathrm{OR}=1.30$; $\mathrm{p}<0.001)$. The interaction between gender and persistent cough was significant in model $1(\mathrm{p}=0.033)$, model $2(\mathrm{p}=0.021)$ and model $3(\mathrm{p}=0.018)$, thereby indicating a significant association between persistent cough and unfavourable QoL restricted to men. All other interactions between gender and chronic symptoms were not significant. 
Table 4 Associations between chronic symptoms and unfavourable QoL (ORs)

\begin{tabular}{|c|c|c|c|c|c|c|}
\hline \multirow[b]{2}{*}{ Chronic symptoms } & \multicolumn{3}{|c|}{ Women $(n=2144)$} & \multicolumn{3}{|c|}{ Men $(n=1973)$} \\
\hline & Model 1† & Model 2† & Model 3† & Model 1† & Model 2† & Model 3† \\
\hline Joint pain & $1.8^{\star \star \star}$ & $1.5^{\star \star}$ & $1.5^{\star \star}$ & $1.5^{\star \star}$ & $1.3^{*}$ & 1.2 \\
\hline Back pain & $1.9^{* * *}$ & $1.7^{\star \star \star}$ & $1.6^{\star \star}$ & $1.4^{*}$ & 1.2 & 1.1 \\
\hline Stomach/intestine problems & $1.5^{\star}$ & 1.3 & 1.2 & $1.5^{\star}$ & 1.2 & 1.2 \\
\hline Mental impairments & 1.2 & 1.0 & 0.9 & $1.9^{\star \star}$ & $1.6^{\star}$ & $1.5^{*}$ \\
\hline Urinary incontinence & 1.3 & 1.0 & 1.0 & $1.7^{\star}$ & 1.4 & 1.3 \\
\hline Impaired sexual life & 1.3 & 1.1 & 1.1 & 1.2 & 1.0 & 1.0 \\
\hline Dyspnoea & $1.6^{*}$ & 1.3 & 1.3 & $2.0^{\star \star \star}$ & $1.7^{\star \star}$ & $1.6^{\star}$ \\
\hline Swollen legs & $2.0^{\star *}$ & 1.5 & 1.4 & $1.6^{*}$ & 1.2 & 1.1 \\
\hline Dizziness/vertigo & 1.6 & 1.2 & 1.1 & $1.8^{\star}$ & 1.4 & 1.3 \\
\hline Skin problems & $1.7^{*}$ & 1.5 & 1.3 & 1.0 & 0.9 & 0.9 \\
\hline Persistent cough & 1.4 & 1.1 & 1.1 & $3.5^{\star \star \star}$ & $3.0^{\star \star}$ & $3.1^{\star \star}$ \\
\hline Chest pain & 1.8 & 1.3 & 1.2 & $5.4^{\star \star}$ & $3.9^{\star \star}$ & $4.2^{\star \star}$ \\
\hline \multicolumn{7}{|l|}{ Number of chronic symptoms } \\
\hline 0 & Ref & & & Ref & & \\
\hline 1 & 1.4 & & & $1.5^{\star}$ & & \\
\hline 2 & $2.4^{* * *}$ & & & $1.7^{\star \star}$ & & \\
\hline 3 & $3.3^{\star \star \star}$ & & & $2.4^{\star * *}$ & & \\
\hline 4 & $2.9^{* \star *}$ & & & $2.8^{\star \star *}$ & & \\
\hline$\geq 5$ & $5.7^{\star \star \star}$ & & & $5.0^{\star \star \star}$ & & \\
\hline
\end{tabular}

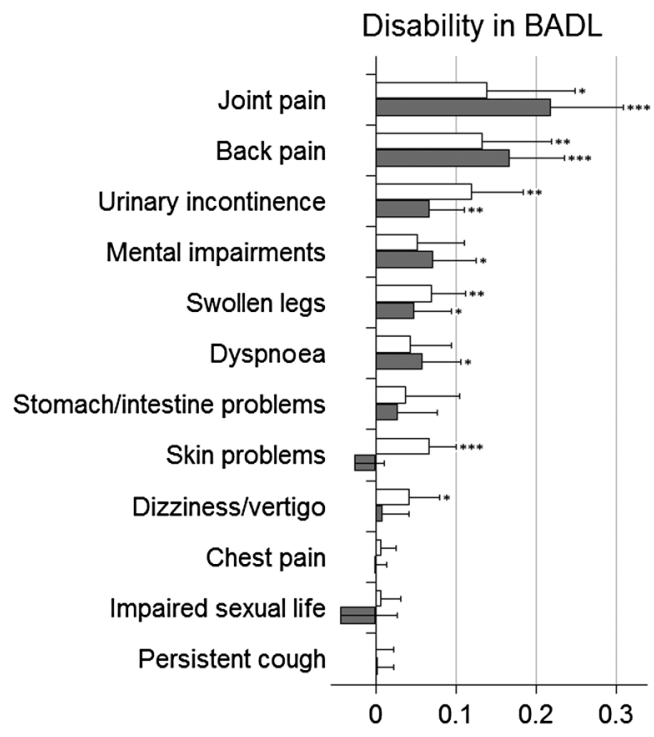

Population attributable fraction

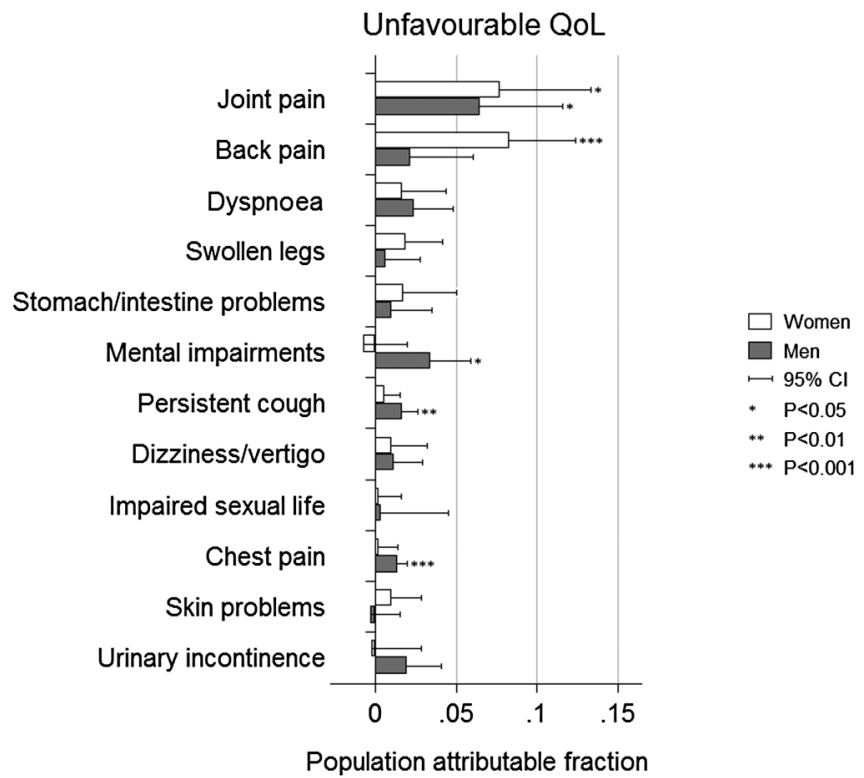

Population attributable fraction

Figure 1 Population attributable fraction of disability in BADL or unfavourable QoL for chronic symptoms in women and men. BADL, basic activities of daily living; QoL, quality of life.

Population attributable fraction

Figure 1 presents chronic symptoms in the order of their contribution to disability in BADL and unfavourable QoL in the total sample. Regarding disability in BADL, the PAF was significant in half of chronic symptoms, although these were not the same in women and men. In both genders, however, joint pain and back pain were the main contributors to disability in BADL. Regarding unfavourable QoL, the most important contributors in women were also joint pain $(7.7 \%$; $\mathrm{p}=0.012)$ and back pain $(8.3 \%$; $\mathrm{p}<0.001)$, whereas the top two factors in men were joint pain $(6.5 \% ; \mathrm{p}=0.019)$ and mental impairments (3.4\%; $\mathrm{p}=0.012)$. Specifically in men, a small but statistically significant proportion of 
unfavourable QoL may be hypothetically reduced by the elimination of persistent cough $(1.7 \%$; $=0.001)$ and chest pain $(1.4 \% ; \mathrm{p}<0.001)$.

\section{DISCUSSION}

\section{Main findings}

In this representative sample of community-dwelling older people, less than one person out of five did not report any chronic symptom and more than half reported multiple chronic symptoms. This observation is largely compatible with the increasingly high frequency of multimorbidity that characterises older age. ${ }^{20}$ From a public health perspective, musculoskeletal symptoms (ie, joint pain and back pain) were the most burdensome chronic symptoms due to their high prevalence and their significant interference with BADL and QoL. Substantial gender differences were observed in the prevalence of chronic symptoms, as well as their associations with, and contribution to disability in BADL and unfavourable QoL.

\section{Prevalence of chronic symptoms}

Women reported a higher number of chronic symptoms than men did. This confirms and extends the gender difference reported in previous studies that did not focus solely on chronic symptoms. ${ }^{4} 7838$ In contrast, Hellström $e t a l^{39}$ did not report any gender difference in the number of symptoms. In their study, Ladwig et al $l^{7}$ suggest that the gender gap may be mediated by a lower socioeconomic status and higher levels of chronic distress in women. The present study pointed to another striking gender difference, that is, the prevalence of impaired sexual life, which was the second most frequently reported chronic symptom in men, but the second least frequently reported one in women. Interestingly, while none of the aforementioned studies assessed impaired sexual life, data from the English Longitudinal Study of Ageing recently indicated that the percentage of individuals aged 70 or above who reported concerns about, or dissatisfaction with, their overall sex life was around $20 \%$ in men but only $5 \%$ in women. ${ }^{40}$

In the present study, joint pain was the most prevalent chronic symptom in both genders. Back pain ranked second in women and third in men. This is consistent with previous population-based studies reporting musculoskeletal symptoms as the most prevalent symptoms ${ }^{38} 39$ or among the most prevalent symptoms ${ }^{45} 8$ in older adults.

\section{Associations between chronic symptoms and disability in BADL}

Importantly, the present study indicates that the accumulation of several chronic symptoms is associated with disability in BADL. Once the number of other chronic symptoms has been accounted for, several chronic symptoms (ie, stomach/intestine problems, dyspnoea, and chest pain in women and men) lose their association with disability in BADL. Since the majority of participants $(58 \%)$ reported multiple chronic symptoms, these findings question the single-disease approach that still prevails in many healthcare systems. As Barnett et $a t^{20}$ underlined in the context of multimorbidity, a comprehensive, patient-centred approach would promote a more efficient coordination of care.

Interestingly, the associations between each chronic symptom and disability in BADL were generally consistent across gender. Nevertheless, skin problems showed the strongest association with disability in BADL in women, whereas this association was not significant in men, despite a similar prevalence of the symptom. Yet it is not clear whether this difference is due to a higher severity of skin problems in women, divergent types of skin diseases in women and men, ${ }^{41}$ or gender-specific interference of skin problems with daily life.

\section{Associations between chronic symptoms and unfavourable QoL}

Persistent cough and chest pain were strongly associated with unfavourable QoL in men, whereas these associations were not significant in women. While the interaction between gender and persistent cough was significant, the lack of a significant interaction between gender and chest pain may be due to the low prevalence of chest pain and the resulting lack of statistical power. In a previous population-based study, ${ }^{42}$ chronic persistent cough was also associated with impairments in health-related QoL, even though older women and men were not analysed separately. Similarly, QoL was found to be worse among patients with chest pain compared with healthy controls, ${ }^{43}$ with significant gender differences in the clinical characteristics of chest pain. ${ }^{44}$ However, this issue has not been specifically addressed in older people. The present study points to genderspecific associations between cardiopulmonary symptoms (ie, persistent cough and chest pain) and QoL in older women and men. Possible explanations include gender differences in coping strategies, and clinical characteristics (including severity) of cardiopulmonary symptoms. For instance, Robb et a $t^{5}$ reported gender differences in coping with functional disability in older married couples. Whereas neuroticism was negatively associated with subjective well-being in husbands and wives, extraversion and social support were linked to subjective wellbeing only in husbands.

\section{Population attributable fraction}

The contribution of chronic symptoms to disability in BADL was about twice as high as that to unfavourable QoL. The multidimensional nature of QoL, which encompasses health as well as factors not directly related to health (eg, material resources, feeling of safety, close entourage), may account for that contrast. ${ }^{22}$ Musculoskeletal chronic symptoms were the strongest contributors to disability in BADL. Indeed, interventions 
targeting prevention of joint pain may reduce disability in BADL by up to $14 \%$ in women and $22 \%$ in men, and interventions targeting prevention of back pain may reduce disability in BADL by up to $13 \%$ in women and $17 \%$ in men. Furthermore, musculoskeletal chronic symptoms strongly contributed to unfavourable QoL, particularly in women. In contrast, preventing chest pain or persistent cough would reduce unfavourable QoL by up to merely $2 \%$ in men only. Despite their high interference with daily life at the patient level, chest pain and persistent cough are not in the front line of preventive actions expecting a huge public health impact.

\section{Strengths and limitations of the study}

This study is based on a representative sample of community-dwelling older men and women. Furthermore, data from the Lc65+ allowed to adjusting for a substantial number of potential confounders. The present study also has some limitations. First, it focused on 14 chronic symptoms, whereas other studies have considered other ones, such as headache, tiredness, impaired hearing/sight and sleeping problems. ${ }^{18} 1939$ Second, each chronic symptom was recorded as present or absent, without attempting to assess severity. Finally, the study's cross-sectional design precludes any causal inference.

\section{CONCLUSION}

In older people, multiple chronic symptoms are the rule rather than the exception. Musculoskeletal chronic symptoms account for a large proportion of the whole chronic symptom iceberg. Owing to their high prevalence and their significant associations with disability and QoL, joint pain and back pain are good targets for preventive interventions seeking to reduce the burden of age-related disability and impairment in QoL.

\author{
Author affiliations \\ ${ }^{1}$ Institute of Social and Preventive Medicine, University of Lausanne Hospital \\ Centre, Lausanne, Switzerland \\ ${ }^{2}$ Service of Geriatric Medicine and Geriatric Rehabilitation, Lausanne \\ University Hospital, Lausanne, Switzerland \\ ${ }^{3}$ Unit of Population Epidemiology, Geneva University Hospitals, Geneva, \\ Switzerland \\ ${ }^{4}$ Department of Ambulatory Care and Community Medicine, University of \\ Lausanne, Lausanne, Switzerland \\ ${ }^{5}$ Department of General Internal Medicine, University Hospital of Bern, Bern, \\ Switzerland \\ ${ }^{6}$ Institute of Primary Health Care (BIHAM), University of Bern, Bern, \\ Switzerland \\ ${ }^{7}$ Pro Senectute Vaud, Lausanne, Switzerland \\ ${ }^{8}$ Pro Senectute Geneva, Geneva, Switzerland
}

Acknowledgements The authors would like to thank all study participants for their involvement, and S Fustinoni for providing statistical advice.

Contributors YH did all the statistical analyses and drafted the manuscript. $\mathrm{YH}$ and BS-E had the idea of the paper and contributed to the interpretation of data. BS-E contributed to the conception of the questionnaire. BS-E and IG contributed to the data collection. BS-E, CB, IG, NR, RG and MD contributed to the critical review of the manuscript. All authors contributed to the study concept and design, and approved the final version.
Funding This work was awarded a prize by the Leenaards Foundation.

Competing interests None declared.

Patient consent Obtained.

Ethics approval The protocol was approved by the Ethics Committees of the Faculty of Biology and Medicine of the University of Lausanne (19/04), and Geneva University Hospitals (11-154).

Provenance and peer review Not commissioned; externally peer reviewed.

Data sharing statement No additional data are available.

Open Access This is an Open Access article distributed in accordance with the Creative Commons Attribution Non Commercial (CC BY-NC 4.0) license, which permits others to distribute, remix, adapt, build upon this work noncommercially, and license their derivative works on different terms, provided the original work is properly cited and the use is non-commercial. See: http:// creativecommons.org/licenses/by-nc/4.0/

\section{REFERENCES}

1. Kroenke K. A practical and evidence-based approach to common symptoms: a narrative review. Ann Intern Med 2014;161:579-86.

2. Last JM, Adelaide DP. The iceberg: 'completing the clinical picture' in general practice. 1963. Int J Epidemiol 2013;42:1608-13.

3. Verbrugge LM, Ascione FJ. Exploring the iceberg. Common symptoms and how people care for them. Med Care 1987;25:539-69.

4. Elnegaard S, Andersen RS, Pedersen AF, et al. Self-reported symptoms and healthcare seeking in the general populationexploring "The Symptom Iceberg". BMC Public Health 2015;15:685.

5. McAteer A. Elliott AM, Hannaford PC. Ascertaining the size of the symptom iceberg in a UK-wide community-based survey. $\mathrm{Br} J \mathrm{Gen}$ Pract 2011;61:e1-11.

6. Elliott AM, McAteer A, Hannaford PC. Revisiting the symptom iceberg in today's primary care: results from a UK population survey. BMC Fam Pract 2011;12:16.

7. Ladwig $\mathrm{KH}$, Marten-Mittag B, Formanek B, et al. Gender differences of symptom reporting and medical healthcare utilization in the German population. Eur J Epidemiol 2000;16:511-18.

8. Tibblin G, Bengtsson C, Furunes B, et al. Symptoms by age and sex. The population studies of men and women in Gothenburg, Sweden. Scand J Prim Healthcare 1990;8:9-17.

9. Krantz G, Ostergren PO. Common symptoms in middle aged women: their relation to employment status, psychosocial work conditions and social support in a Swedish setting. J Epidemiol Community Health 2000;54:192-9.

10. Bardel A, Wallander MA, Wedel $\mathrm{H}$, et al. Age-specific symptom prevalence in women 35-64 years old: a population-based study. BMC Public Health 2009;9:37.

11. Edmond SL, Felson DT. Prevalence of back symptoms in elders. J Rheumatol 2000;27:220-5.

12. Salazar R, Royall DR, Palmer RF. Neuropsychiatric symptoms in community-dwelling Mexican-Americans: results from the Hispanic Established Population for Epidemiological Study of the Elderly (HEPESE) study. Int J Geriatr Psychiatry 2015;30:300-7.

13. Forlani M, Morri M, Belvederi Murri M, et al. Anxiety symptoms in 74 + community-dwelling elderly: associations with physical morbidity, depression and alcohol consumption. PLOS ONE 2014:9:e89859.

14. Stenzelius K, Westergren A, Mattiasson A, et al. Older women and men with urinary symptoms. Arch Gerontol Geriatr 2006;43:249-65.

15. Morgan R, Pendleton N, Clague JE, et al. Older people's perceptions about symptoms. Br J Gen Pract 1997;47:427-30.

16. Brody EM, Kleban MH. Physical and mental health symptoms of older people: who do they tell? J Am Geriatr Soc 1981;29:442-9.

17. Brody EM, Kleban MH, Moles E. What older people do about their day-to-day mental and physical health symptoms. J Am Geriatr Soc 1983;31:489-98.

18. Whitson HE, Sanders LL, Pieper CF, et al. Correlation between symptoms and function in older adults with comorbidity. J Am Geriatr Soc 2009;57:676-82

19. Walke LM, Gallo WT, Tinetti ME, et al. The burden of symptoms among community-dwelling older persons with advanced chronic disease. Arch Intern Med 2004;164:2321-4.

20. Barnett K, Mercer SW, Norbury M, et al. Epidemiology of multimorbidity and implications for healthcare, research, and medica education: a cross-sectional study. Lancet 2012;380:37-43.

21. Santos-Eggimann B, Karmaniola A, Seematter-Bagnoud L, et al. The Lausanne cohort Lc65+: a population-based prospective study 
of the manifestations, determinants and outcomes of frailty. BMC Geriatr 2008;8:20.

22. Henchoz Y, Meylan L, Goy R, et al. Domains of importance to the quality of life of older people from two Swiss regions. Age Ageing 2015;44:979-85.

23. Alcser $\mathrm{KH}$, Benson G, Börsch-Supan A, et al. The Survey of Health, Ageing, and Retirement in Europe-methodology. Manheim: Mannheim Research Institute for the Economics of Ageing, 2005:175.

24. Katz S, Downs TD, Cash HR, et al. Progress in development of the index of ADL. Gerontologist 1970;10:20-30.

25. Hartigan I. A comparative review of the Katz ADL and the Barthel Index in assessing the activities of daily living of older people. Int J Older People Nurs 2007;2:204-12.

26. Buurman BM, van Munster BC, Korevaar JC, et al. Variability in measuring (instrumental) activities of daily living functioning and functional decline in hospitalized older medical patients: a systematic review. J Clin Epidemiol 2011;64:619-27.

27. Leplège A, Ecosse E, Verdier A, et al. The French SF-36 Health Survey: translation, cultural adaptation and preliminary psychometric evaluation. J Clin Epidemiol 1998;51:1013-23.

28. Sloan JA, Aaronson N, Cappelleri JC, et al. Assessing the clinical significance of single items relative to summated scores. Mayo Clin Proc 2002;77:479-87.

29. Gill TM, Feinstein AR. A critical appraisal of the quality of quality-of-life measurements. JAMA 1994;272:619-26.

30. Henchoz Y, Botrugno F, Cornaz S, et al. Determinants of quality of life in community-dwelling older adults: comparing three cut-offs on the excellent-to-poor spectrum. Qual Life Res 2016 doi:10.1007/ s11136-016-1394-3 [Epub ahead of print: 24 Aug 2016].

31. UNESCO. International Standard Classification of Education. UNESCO Institute for Statistics, 2011. http://www.uis.unesco.org/ Education/Pages/international-standard-classification-of-education. aspx (accessed 26 Oct 2016).

32. Whooley MA, Avins AL, Miranda J, et al. Case-finding instruments for depression. Two questions are as good as many. $J$ Gen Intern Med 1997;12:439-45.

33. Alexandre Tda S, Corona LP, Nunes DP, et al. Gender differences in incidence and determinants of disability in activities of daily living among elderly individuals: SABE study. Arch Gerontol Geriatr 2012:55:431-7.

34. Orfila F, Ferrer M, Lamarca R, et al. Gender differences in health-related quality of life among the elderly: the role of objective functional capacity and chronic conditions. Soc Sci Med 2006;63:2367-80.

35. Newson RB. Attributable and unattributable risks and fractions and other scenario comparisons. Stata J 2013;13:672-98.

36. Greenland S, Drescher K. Maximum likelihood estimation of the attributable fraction from logistic models. Biometrics 1993;49:865-72.

37. White IR, Royston P, Wood AM. Multiple imputation using chained equations: issues and guidance for practice. Stat Med 2011;30:377-99.

38. Eckerblad J, Theander K, Ekdahl A, et al. Symptom burden in community-dwelling older people with multimorbidity: a cross-sectional study. BMC Geriatr 2015;15:1.

39. Hellström Y, Persson G, Hallberg IR. Quality of life and symptoms among older people living at home. J Adv Nurs 2004;48: 584-93.

40. Lee DM, Nazroo J, O'Connor DB, et al. Sexual health and well-being among older men and women in England: findings from the English Longitudinal Study of Ageing. Arch Sex Behav 2016;45:133-44.

41. Yalçin B, Tamer E, Toy GG, et al. The prevalence of skin diseases in the elderly: analysis of 4099 geriatric patients. Int $J$ Dermatol 2006;45:672-6.

42. Song WJ, Morice AH, Kim MH, et al. Cough in the elderly population: relationships with multiple comorbidity. PLOS ONE 2013;8:e78081.

43. Webster R, Norman P, Goodacre S, et al. The prevalence and correlates of psychological outcomes in patients with acute non-cardiac chest pain: a systematic review. Emerg Med J 2012;29:267-73.

44. Bösner S, Haasenritter J, Hani MA, et al. Gender differences in presentation and diagnosis of chest pain in primary care. BMC Fam Pract 2009;10:79.

45. Robb C, Small B, Haley WE. Gender differences in coping with functional disability in older married couples: the role of personality and social resources. Ageing Ment Health 2008;12:423-33. 